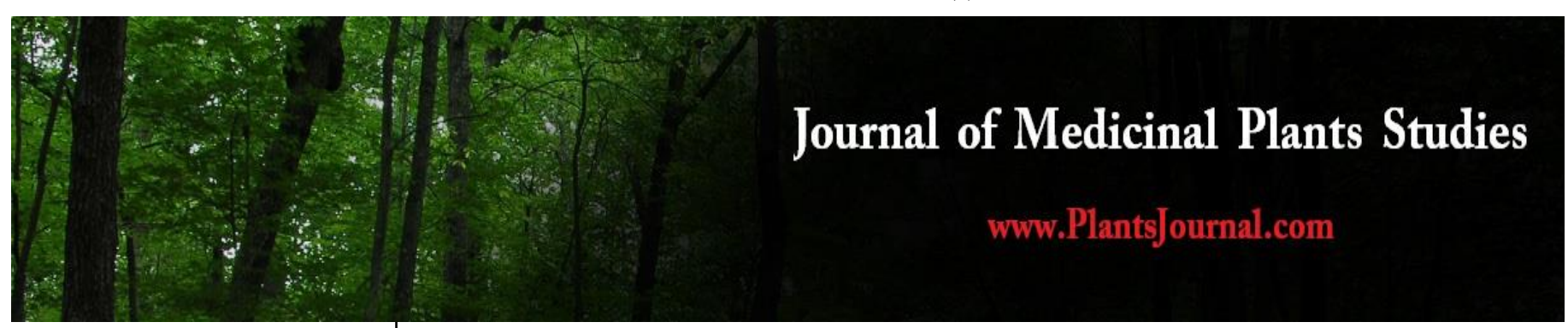

ISSN (E): 2320-3862

ISSN (P): 2394-0530

NAAS Rating: 3.53

www.plantsjournal.com

JMPS 2020; 8(5): 05-13

(C) 2020 JMPS

Received: 10-07-2020

Accepted: 12-08-2020

Zainab Al Lawati

Emergency Medicine Specialist (OMSB EM, ABEM), Ministry of Health (MoH), Muscat, Oman

Alaa Al Lawati

Medical Officer (MBBS),

Ministry of Health (MoH),

Muscat, Oman

Corresponding Author:

Zainab Al Lawati

Emergency Medicine Specialist (OMSB EM, ABEM), Ministry of Health $(\mathrm{MoH})$, Muscat, Oman

\section{Uses, local practices and side effects of six medicinal plants in the sultanate of Oman: A review article}

\section{Zainab Al Lawati and Alaa Al Lawati}

DOI: https://doi.org/10.22271/plants.2020.v8.i5a.1185

\begin{abstract}
Over the years, ethno-botanical and traditional medicine has received great interest by our society. The World Health Organisation (WHO) has sixty herbal medicines registered for ethno-medical usage in Oman, with acknowledged use by $80-99 \%$ of the population. These plants are, collectively, believed to have analgesic, anti-microbial, anti-oxidant, anti-cancer, anti-viral and in some instances immune modulatory properties. Despite being widely used locally, the majority of people are oblivious about the possible side effects that follow erroneous usage. As plants have been widely incorporated in traditional medicine, plant poisoning has become a worldwide concern. Locally, these plants appear to be readily available all over the Country. This article discusses six different plants that are used frequently by the natives of Oman and are widely available here; being Nerium oleander, Adenium obesum, Euphorbia cactus, Ficus cordata, Datura metel and Calotropis procera. The aim is to highlight the distribution of those plants in the Country, their medical and non-medical uses, poisonous parts and finally toxicity and possible side effects. The objective is to increase awareness among physicians, health care workers and the public about plants and their effects.
\end{abstract}

Keywords: Toxicology, traditional healers, ethno-medicine, household and roadside shrubs, poisonous plants in Oman, cardiotoxicity

\section{Introduction}

Over the years, ethno-botanical and traditional use of natural compounds, particularly those derived from plant origin, has received great interest by our society. Plants in use are widely known for their worth, and are generally believed to be harmless for human usage. This practice has endured years of modernisation, and the knowledge and experience pertaining to its use continues to be passed on verbally from older generations to the younger ones. A thorough review of the published literature and unpublished material held at Oman Botanic Garden shows that herbal medicine is a popular remedy among various ethnicities and tribes, and is densely incorporated in traditional and ayurvedic medical practice around the globe. On the other hand, plant chemicals are also involved in the production of $25 \%$ of the prescribed pharmaceutical drugs available in the market ${ }^{[1]}$.

The practice of medicine in Oman has been swayed by multiple schools of practice in the region due to its topographic location. These schools include; Indian healers, Ayurvedic therapists, African rituals, Persian-Islamic practitioners and Portuguese Galenic-Hippocratic humoralism $\left(16^{\text {th }}\right.$ century) ${ }^{[2]}$. This ultimately created a diverse history of medicine in the Country. In terms of practice, the two main schools implemented are western allopathic medicine and traditional complementary medicine. The latter has been regulated in the Country since $2001^{[1]}$. The World Health Organisation (WHO) has sixty herbal medicines registered for ethno-medical usage in Oman, with acknowledged use by $80-99 \%$ of the population ${ }^{[3]}$. Despite being widely used locally, the majority of people are oblivious about the possible side effects that follow erroneous usage. The traditional wisdom accumulated over generations of trial and error have had, in some instances, some serious implications, particularly when the user is ignorant about the toxicities of the chemical components involved. Diurnal variation also results in certain chemicals being more concentrated during certain parts of the day. Therefore, preparing the correct strength of the plant is key to forming the proper composition of the remedy. 
As plants have been widely incorporated in traditional medicine, plant poisoning has become a worldwide concern. Some of these plants were imported from different places, and at present appear to be readily available all over the Country, beautifying main roads, neighbourhood sidewalks, public parks and private gardens. This is due to having a pleasant appearance and requiring minimal level of care, making it in close reach to small hands. Locally, more than $70 \%$ of cases involve children aged 5 and below ${ }^{[4]}$. The aim of this article is to discuss some of the plants that are still commonly used in Oman and widely available around us. The main aspects that will be highlighted are; plant distribution and location of availability, medical and non-medical uses, poisonous parts and possible side effects and toxicities. The objective is to increase awareness among physicians, health care workers and the public about plants and their effects to ensure safe usage by the public.

\section{Discussion}

\section{Nerium oleander}

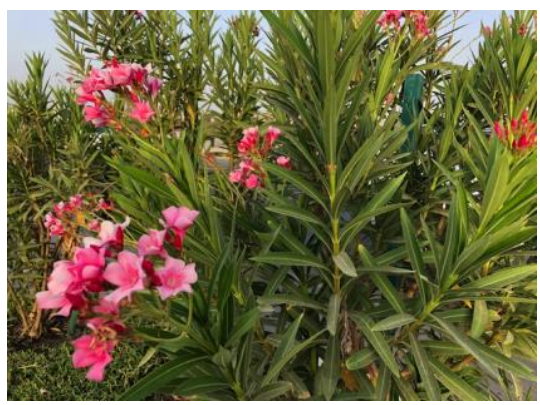

Fig 1: Courtesy Dr. Z Allawati, Beach Road, Muscat, Oman (July 2020)

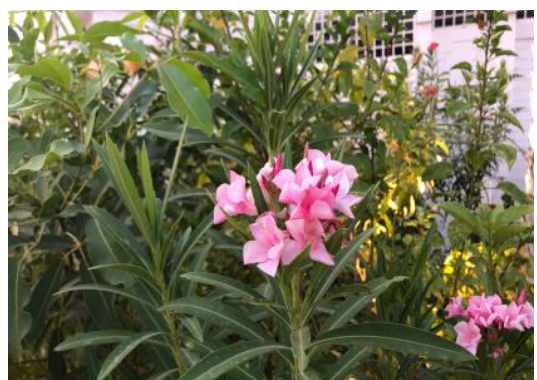

Family: Apocynaceae (Dogbane)

\section{Location}

Nerium oleander can be found everywhere around us. It is cultivated throughout the Country due to its pleasant appearance and low maintenance. It can be found inside house gardens, public parks and also as roadside shrubs. It is also found in the lower altitudes of mountains, in wadis and aflaj, often near the water ${ }^{[5]}$.

Uses

The leaf extracts have been used in traditional medicine as a treatment modality for cough from bronchitis ${ }^{[6]}$. The sap is used in treating joint pain, joint swelling and skin eruptions ${ }^{[7]}$. Moreover, the leaves, sap and stem are together used for treating headache and snakebites ${ }^{[7]}$. In the past, Nerium oleander was used in Africa as arrow poison, due to containing cardioactive steroids ${ }^{[8]}$.

\section{Poisonous parts}

All parts in the Nerium oleander plant are poisonous, with the toxin mostly being concentrated in the roots and seeds ${ }^{[9]}$. It contains cardiac glycosides, which can produce more gastrointestinal effects than those from digoxin ${ }^{[9]}$.

\section{Side effects}

The symptoms can range from nausea and vomiting to cramping and bloody diarrhea. Moreover, it can cause irritation to the mucosal membranes, resulting in perioral burning and increased salivation ${ }^{[10]}$. Oleander is also toxic to the central nervous system, and toxicity can manifest in the form of confusion, dizziness, drowsiness, weakness and visual disturbances ${ }^{[10]}$.

The most serious side effects of Nerium oleander are hyperkalaemia and cardiac toxicity, including sinus bradycardia, ventricular tachydysrhythmias, premature ventricular contractions and heart block ${ }^{[8]}$. Electrocardiography often reveals an increased PR interval, decreased QRS-T interval, with $\mathrm{T}$ wave flattening or inversion ${ }^{[9]}$. These clinical features result from direct cardiac glycoside toxicity and increased vagal tone, where the severity of poisoning correlates directly with the level of hyperkalaemia ${ }^{[9]}$.

Fig 2: Courtesy Dr. Z Allawati, Shatti Al Qurum, Muscat, Oman (June 2020)

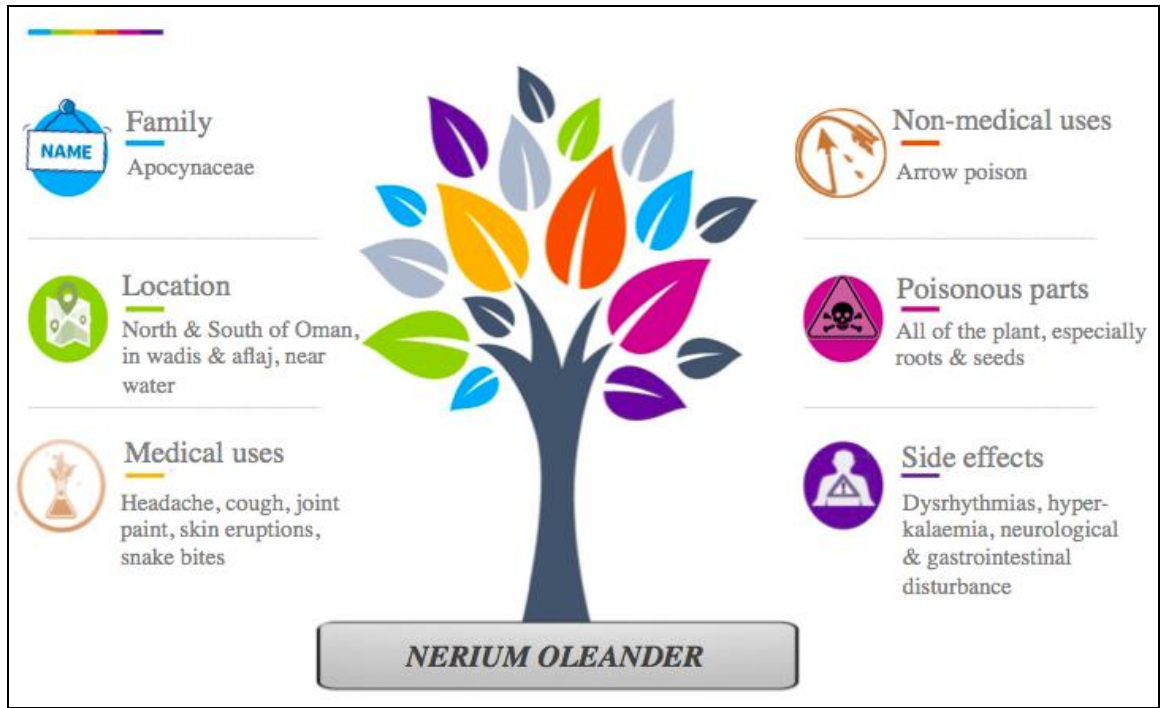

Infograph (1) 


\section{Adenium obesum (Desert Rose, Impala lily, Mock Azalea)}

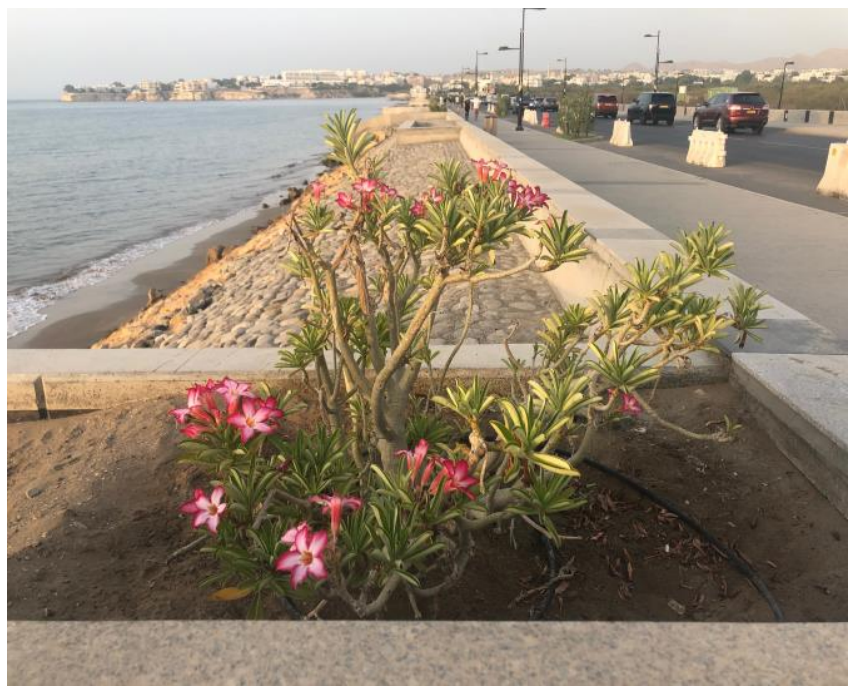

Fig 3: Courtesy Dr. Z Allawati, Beach Road, Muscat, Oman (June 2020)

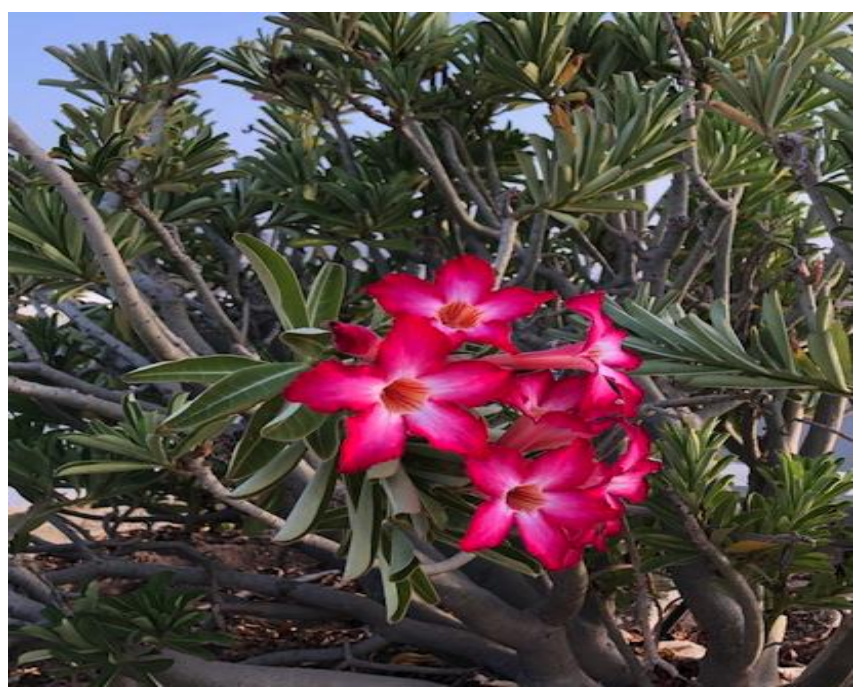

Fig 4: Courtesy Dr. Z Allawati, Al Elam Area, Muscat, Oman (June 2020)
Family: Apocynaceae

\section{Location}

Adenium obesum has since the 80 's been described as one of the most eccentric yet appealing plants growing in the South of Oman ${ }^{[6]}$. It is available in abundance there, mainly in low dry rocky hills, in the foot of the escarpment of mountains reaching to the sea, in addition to the drier north-facing slopes of the mountains. It is also readily available in the North of Oman, where it's used as an ornamental plant for houses and roads ${ }^{[6]}$

\section{Uses}

This plant is believed to have anti-microbial, anti-oxidant, anti-cancer, anti-viral and immune modulating properties ${ }^{[11]}$. The sieved liquid is extracted from the stem, then applied locally to swellings, painful joints, sprains and dislocations. It is applied on paralysed limbs, sites of pain in cases of sciatica or lumbago, and to the whole body of a patient suffering from generalised oedema ${ }^{[12]}$. It is also believed to speed the healing process of wounds and skin infections ${ }^{[12]}$, and is used for treating headache, tooth decay and venereal diseases [13, 14]. Adenium obesum also has non-clinical uses. The sap is believed to be efficacious in collaring illness caused by the evil eye, and is used as a protection tool against evil spirits and ill-wishers ${ }^{[13]}$. Due to its chemical composition, the latex is also used in some places as a pesticide ${ }^{[11]}$

\section{Poisonous parts}

All parts of this plant are poisonous to livestock. Certain folklore is attached to this plant in Southern Oman, where it is believed that snakes obtain their poison from it ${ }^{[6]}$.

\section{Side effects}

This comely looking plant contains cardio-active steroids resembling digitalis. Toxicity from those steroids depends on the amount ingested. The most common effects following acute ingestion of cardiac glycosides are nausea, vomiting, abdominal pain, lethargy and decreased heart rate ${ }^{[8]}$. Several forms of dysrhythmias (sinus bradycardia, premature ventricular contractions, atrioventricular conduction defects, or ventricular tachydysrhythmias) can be seen with severe toxicity, in addition to hyperkalemia ${ }^{[12]}$.

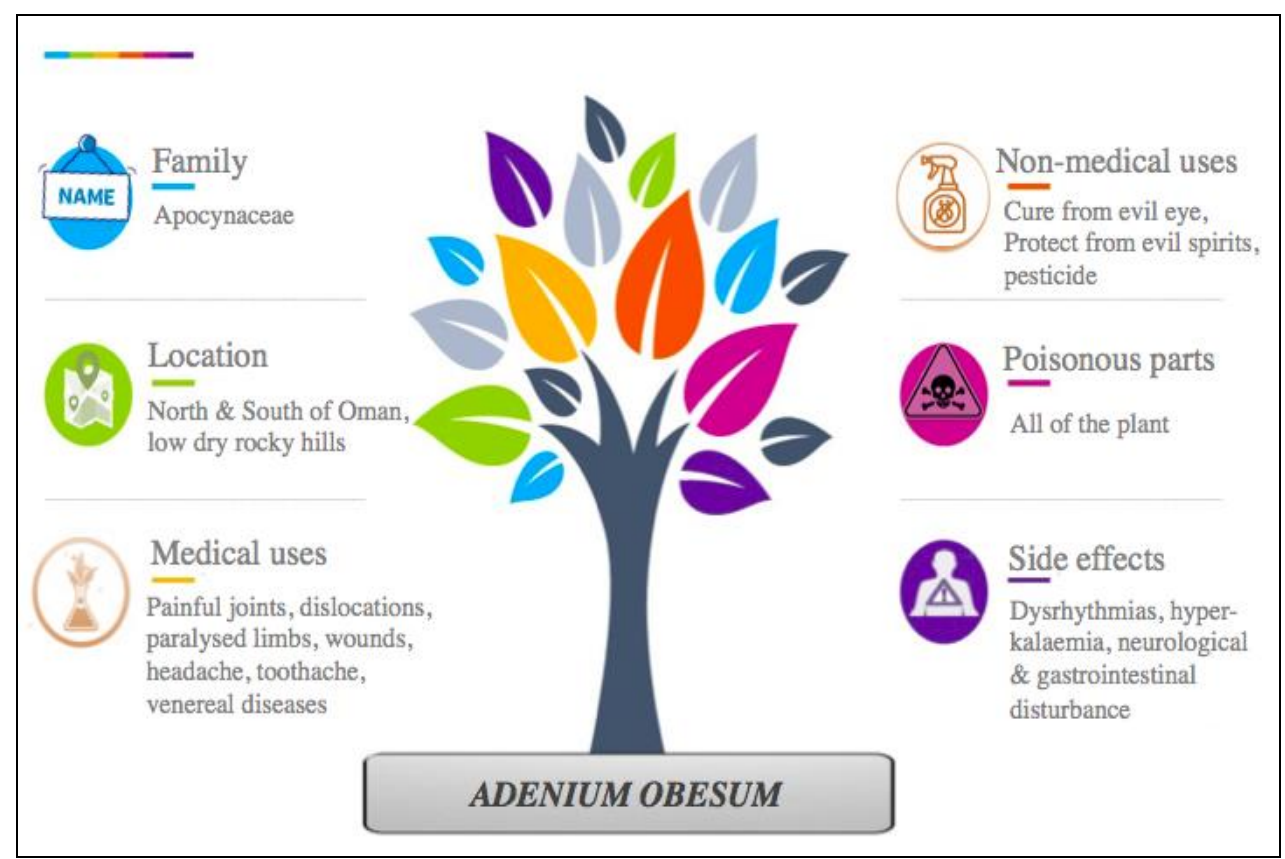

Infograph (2) 


\section{Euphorbia cactus}

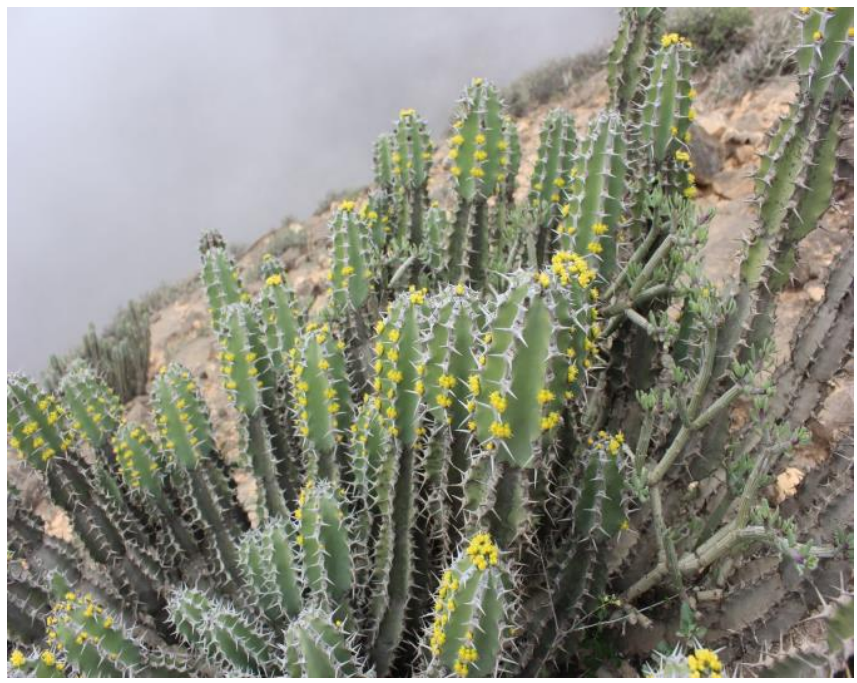

Fig 5: Courtesy Oman Botanic Garden (May 2018)

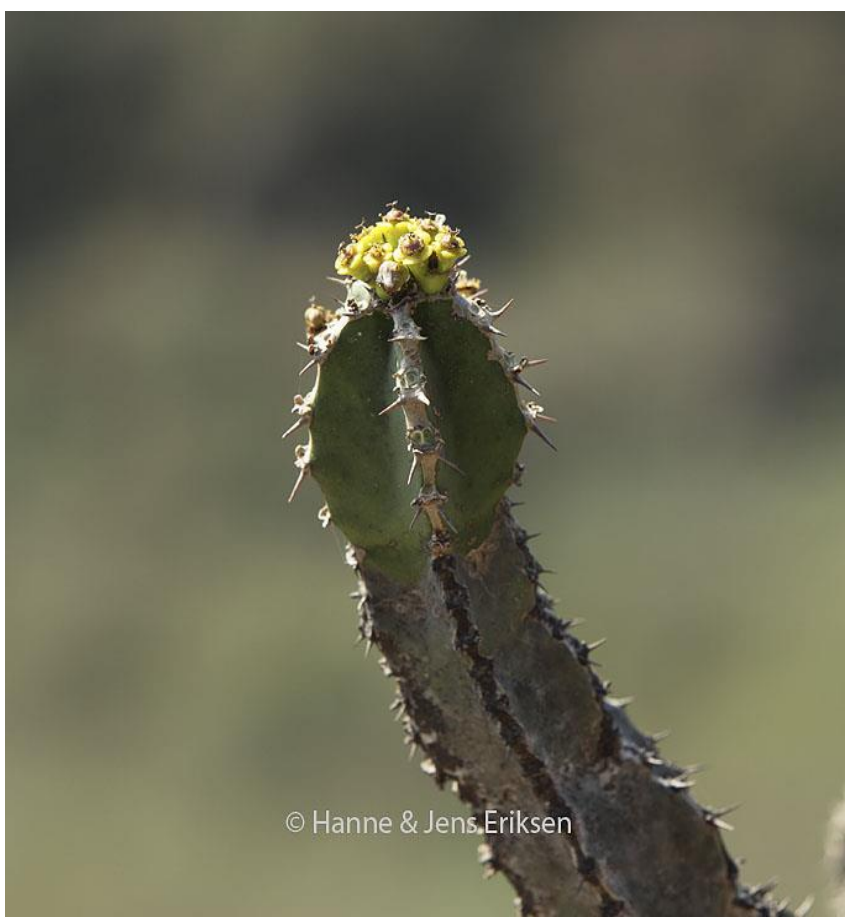

Fig 6: [http://www.birdsoman.com/Flowers/29Euphorbiales/Euphorbiacactus/Euphorbiacactus.htm]
Family: Euphorbiaceae

\section{Location}

Euphorbia cactus is native to South Africa, where it stands out in the dry sub-lands ${ }^{[15]}$. In Oman, it is found in the Southern region (Dhofar), on dry foothills of the slopes of mountains. It is occasionally found on the coastal cliffs of the wet escarpment mountains ${ }^{[6]}$.

\section{Uses}

In traditional medicine, more than $5 \%$ of Euphorbia species is utilized in treating ailments. The latex was extracted from the stem then used for treating a variety of skin conditions, including ones causing severe itching, like scabies and ringworm. The juice, however, was never allowed to touch an open cut, as inflammation \& sometimes ulceration would ensue. It was also rubbed around the base of a boil, in an attempt to draw out the pus. The latex was used for toothache as well, where a single drop was put on the painful tooth to anaesthetize it, allowing further care to be provided, such as extraction ${ }^{[6]}$. The liquid extract was rarely used on young children or small livestock, due to the pain it caused. It is also known to have cathartic effects, and was given to relief constipation ${ }^{[16]}$. In dry seasons, the whole plant is one the main sources of nutriment for camels ${ }^{[5]}$.

\section{Poisonous parts}

The poison is concentrated in the sap, and is mainly attributed to the chemical compound 'diterpene'. On cutting the spurges, vapours can cause irritation to mucosal membranes despite being meters away, and the fumes are known to be highly toxic ${ }^{[16]}$.

\section{Side effects}

Some species are poisonous more than others, thus some suffer greatly even if the skin comes into contact with small amounts of the latex. The main side effect of Euphorbia cactus is local skin irritation, namely dermatitis and caustic burn ${ }^{[17,18]}$. Euphorbia species are also known to cause eye injury. On reviewing the literature, it becomes evident that there is a seemingly typical syndrome of 'Euphorbia keratopathy, the severity of which depends on the species involved [19]. Injury can range from kerato-conjunctivitis to complete blindness ${ }^{[20]}$. One article dated from 1935 reported a case of a physician who dosed himself a certain amount of the sap and following that, passed away from it ${ }^{[21]}$.

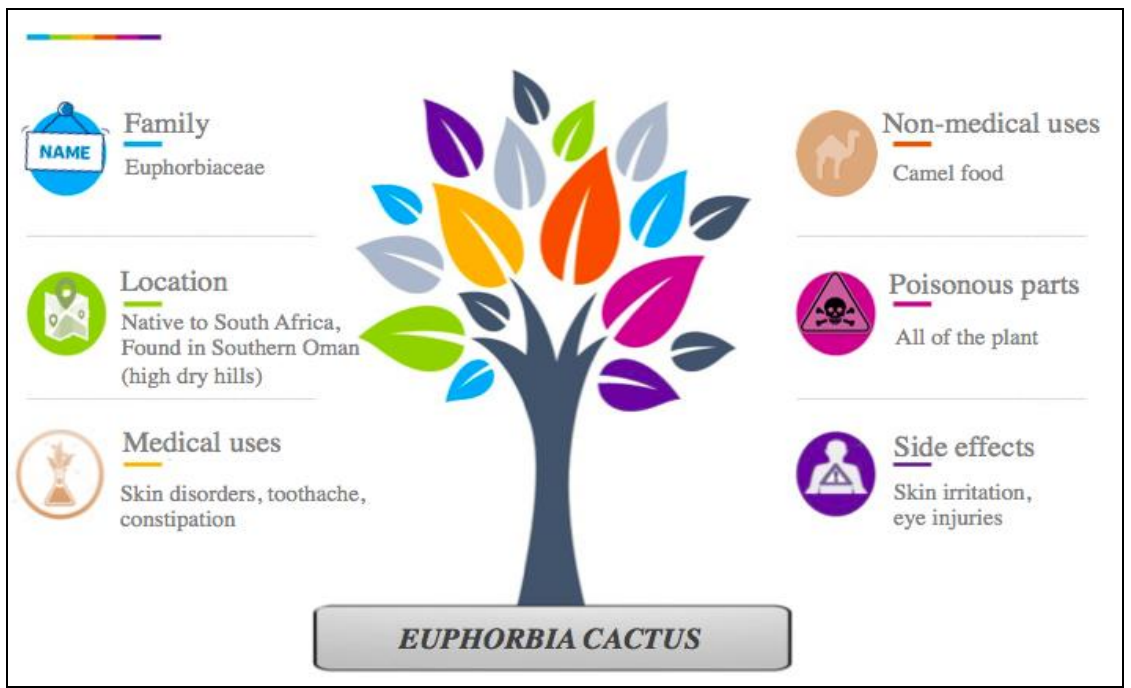

Infograph (3) 


\section{Ficus cordata}

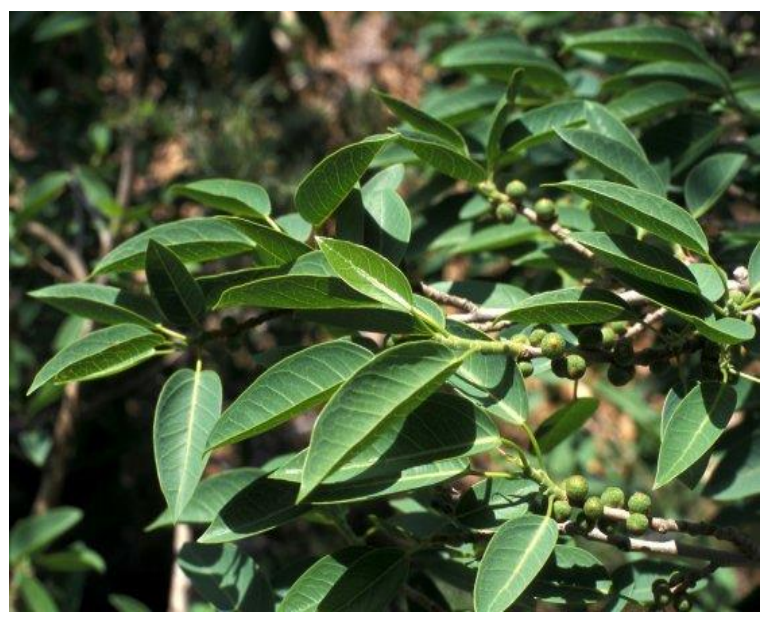

Fig 7:

[http://www.figweb.org/Ficus/Subgenus_Urostigma/Section_Urostig ma/Subsection_Urostigma/Ficus_cordata_cordata.htm]

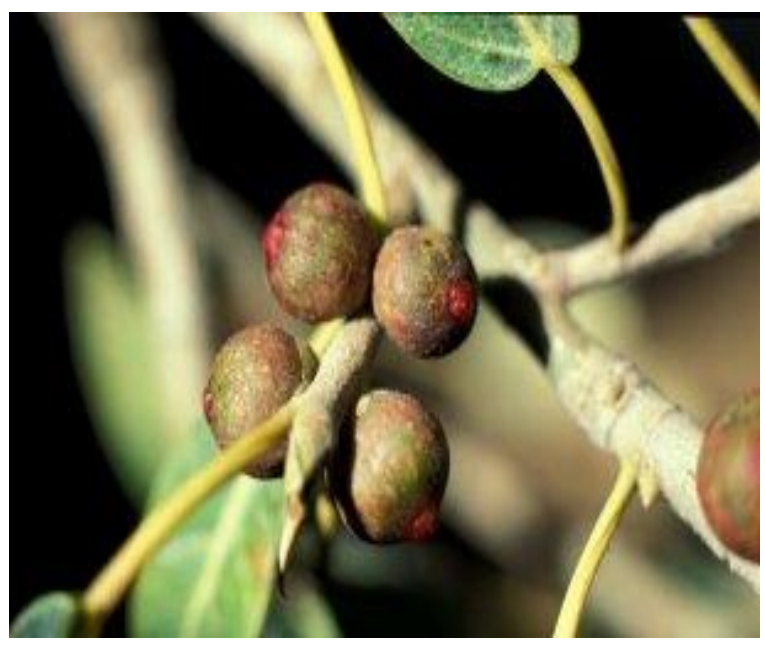

Fig 8:

[http://www.figweb.org/Ficus/Subgenus_Urostigma/Section_Urostig ma/Subsection_Urostigma/Ficus_cordata_cordata.htm]

Family: Moraceae

Location

This plant is widespread in semi-dry to dry regions of the western parts of South Africa ${ }^{[22]}$. In the Sultanate of Oman, it's available throughout the country. It tends to be absent in dry sandy desert areas, but present around desert oasis. It is also found in the foothills, upper altitudes of northern \& southern mountains, and around valleys (wadis) \& crevices (aflaj) ${ }^{[23]}$. In private premises, it tends to be grown around permanent \& seasonal water pools.

\section{Uses}

The folk medicine men in Oman used to take the silvers of the under bark, grind it into a powder and then turn it into a poultice. This paste was then applied as a dressing onto wounds, specifically for weeping skin abrasions and festering sores, in an attempt to decrease bleeding from fresh wounds [7]. The leaves were then placed over the site to form a bandage ${ }^{[7]}$. Moreover, The tree sap was used for bites, burns and toothache. The small leaves had several uses; they were ingested for relieving from bloating, drunk for decreasing blood sugar in diabetics, and applied with the fruits locally for treating bruised and crushed digits ${ }^{[7,24]}$. The leaves were also boiled and applied over the whole body for those believed to suffer from evil spirits jinn) [7]. In traditional African medicine, it is used in the treatment of diarrhea and tuberculosis ${ }^{[25]}$. Ficus cordata has also been reported to have anti-microbial properties ${ }^{[26]}$.

\section{Poisonous parts}

This plant is poisonous all over. It is said that eating the fresh fruit from the trees causes 'madness'. The fresh fruits, while still on the branch, are regarded as highly toxic to human and livestock. On the other hand, those that have ripened and fallen off the branch, were eaten by livestock (and humans too in hard times) with no apparent ill effects ${ }^{[24,27]}$.

\section{Side effects}

Ficus cordata mainly causes neurotoxicity, with symptoms ranging from tremor, tetanic spasms, hyperesthesia, ataxia, fits and death ${ }^{[28]}$. A study done in 1994 on cattle reported multiple changes occurring at a microscopic level following ingestion of Ficus cordata, namely being central nervous system odeoma, focal demyelination and disseminated necrosis of hepatocytes ${ }^{[28]}$. However, a recent chemometric analysis done on three subspecies in the ficus family, including Ficus cordata, noted antioxidant and hepatoprotective traits of the plants analysed ${ }^{[27]}$.

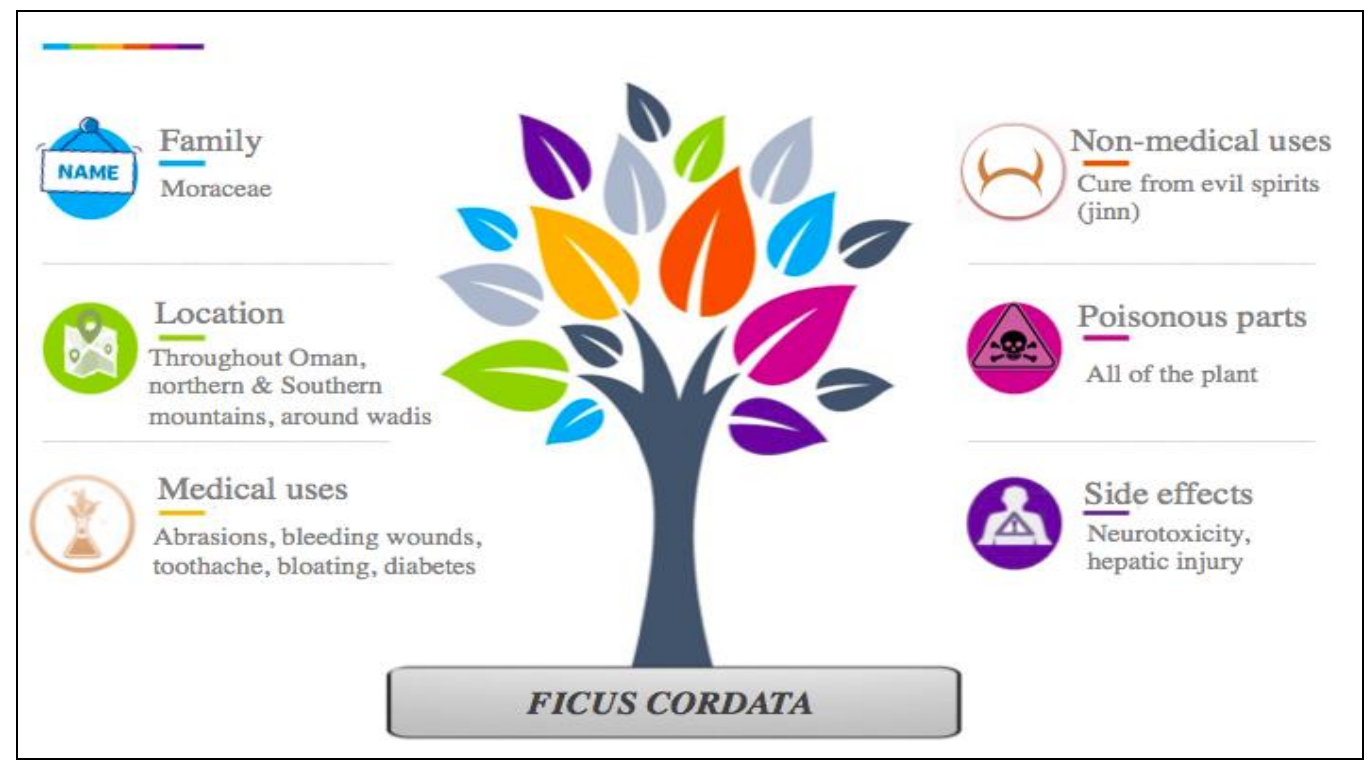

Infograph (4)

$\sim 9 \sim$ 


\section{Datura metel (Devil's Trumpet)}

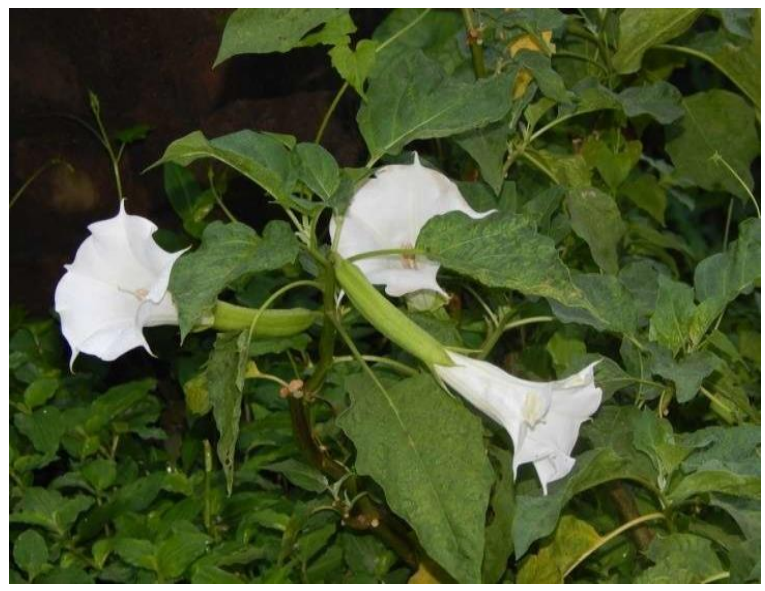

Fig 9: Bera B, Parui S \& Mondal A (2015) Variation in the Protein Profile of the Allergenic Pollen of Datura metel with different stages of maturity, International Journal of Current Research, 7 (6): 1717417180

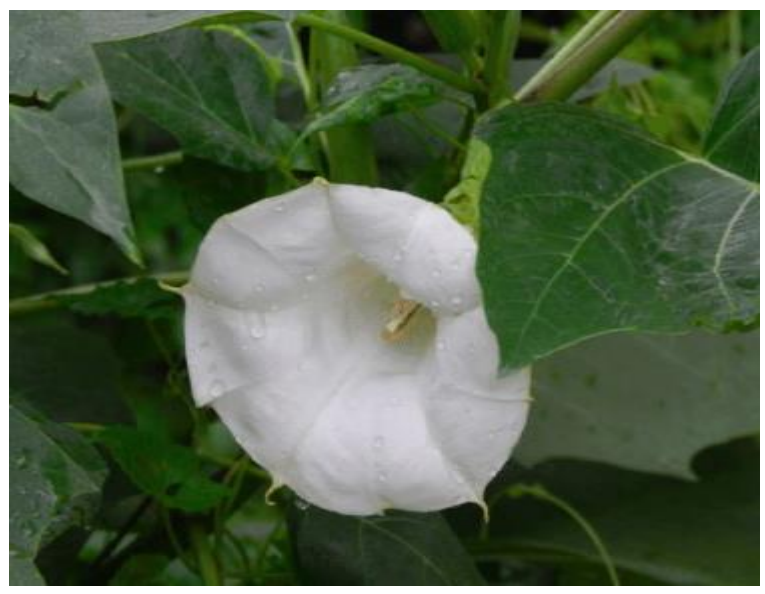

Fig 10: Bera B, Parui S \& Mondal A (2015) Variation in the Protein Profile of the Allergenic Pollen of Datura metel with different stages of maturity, International Journal of Current Research, 7 (6): 1717417180

Family: Solanaceae (Deadly Nightshade)
This shrub is hard to miss. It is native to subtropical regions of the Americas, but has been cultivated throughout the world. It prefers warm temperatures, with rich moist soils ${ }^{[29]}$. In Oman, this plant is found in the northern and southern regions. It grows in date gardens and on disturbed grounds.

\section{Uses}

Datura metel is believed to have multiple therapeutic uses. It is used as an anti-inflammatory, anti-bacterial, anti-asthmatic, anti-rheumatic, anti-oxidant and hypoglycaemic agent ${ }^{[30]}$. In the past, the ripe seeds were used for treating respiratory tract infections ${ }^{[24]}$, and as anaesthetic and sedative agents, prior to operations and during childbirth ${ }^{[31]}$. The fruits and leaves were also used for treating skin sores, eruptions and swollen joints ${ }^{[7]}$. Moreover, the roots were worn as a protection tool against devils (jinn) and the evil eye ${ }^{[24]}$. It was also believed that sprinkling it around the house breaks vile spells ${ }^{[32]}$. Studies further suggest that the plant possesses anti-cancer properties. Its medicinal use, however, has yet to be established ${ }^{[30]}$.

\section{Poisonous parts}

This plant contains three tropane alkaloids; scopolamine, hyoscyamine and atropine. They are found throughout the plant, being concentrated mainly in the flowers and seeds ${ }^{[30]}$. The former crosses the blood-brain barrier, resulting in neurological manifestations like delirium, drowsiness, agitation and dementia. The latter results in blurred vision, dry flushed skin and hyperthermia.

\section{Side effects}

The symptoms of datura poisoning are remembered as the 10 D's, being: 1) dry mouth; 2) dysphagia; 3) dilated pupils; 4) diplopia; 5) dry hot skin, with flushing and hyperpyrexia; 6) drunken gait (ataxia), hyper-reflexia, and convulsions; 7) delirium with hallucinations, agitation, amnesia, and incoherence; 8) delusions; 9) dysuria, retention, and bladder distension; and 10) death, preceded by tachycardia, arrhythmias, coma, and respiratory depression ${ }^{[30]}$. It is classed as a weed, where its' presence can be harmful to other plants [7].

\section{Location}

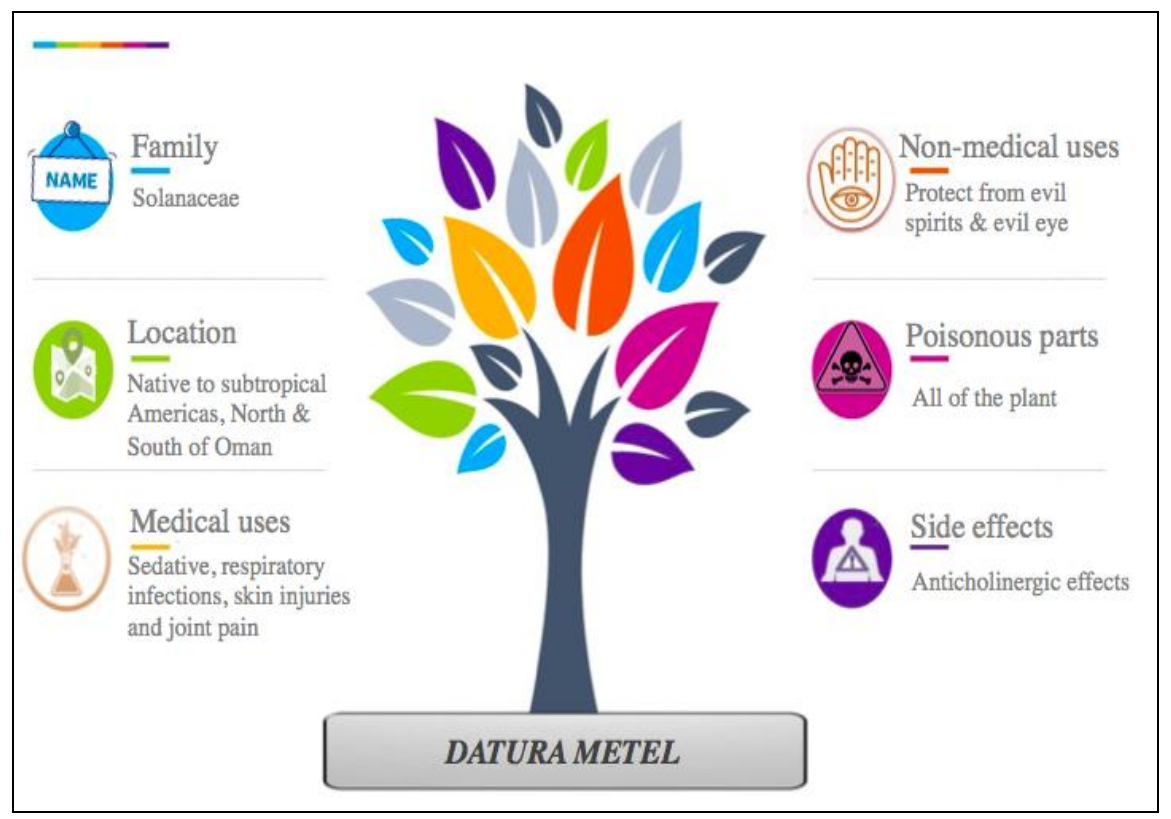

Infograph (5) 


\section{Calotropis procera (Sodom's Apple, Rubber Tree)}

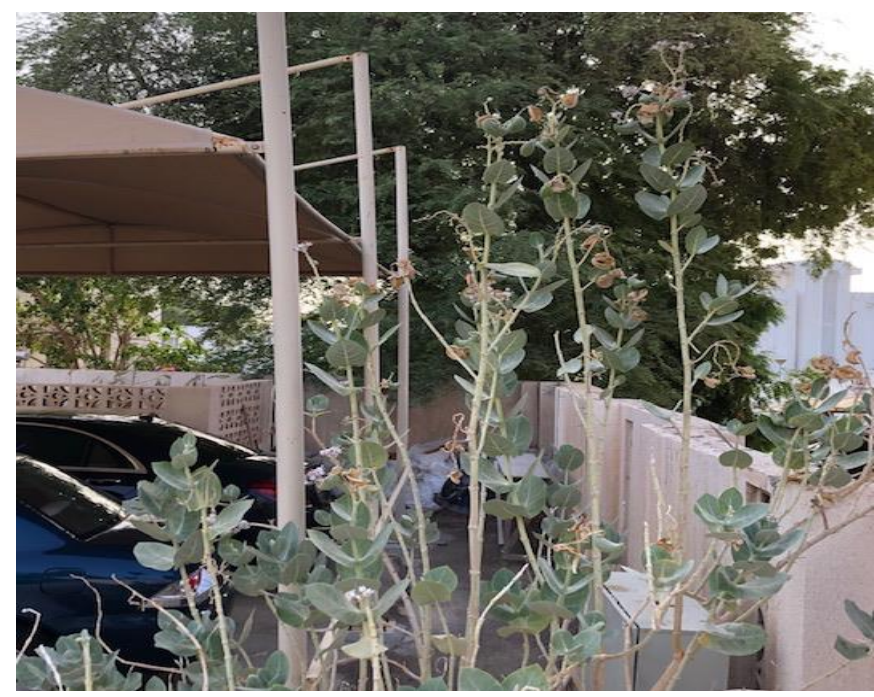

Fig 11: Courtesy Dr Z Allawati, Al Elam Area, Muscat, Oman (June 2020)

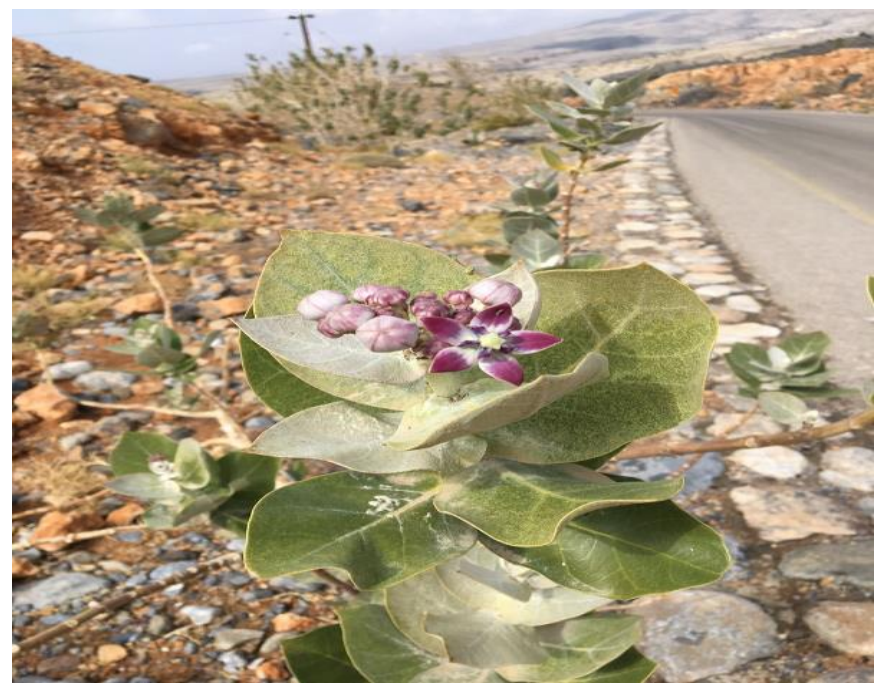

Fig 12: Courtesy Oman Botanic Garden (May 2018)

Family: Apocynaceae

\section{Location}

This plant has an advantage of growing in abundance in unfavourable harsh conditions. It can withstand warm climates, enduring dry, sandy, and alkaline soils ${ }^{[33]}$. This makes this shrub ubiquitous to the Sultanate, being noted on several roadsides and inside private gardens and farms.

\section{Uses}

Calotropis procera is a very common plant in Oman and is wildly used in traditional medicine. It has an un-palatable texture and flavor, making its' uses mostly external ${ }^{[7]}$. The leaves, flowers, roots and root barks are all incorporated in the decoction process, the product of which is then used as an analgesic, anti-fungal and febrifugic agent. Headache, tooth pain and arthritic joint pain are all ailments believed to benefit from this herb ${ }^{[23]}$. The poultice of dried leaves is used for speeding up the healing of skin disorders, infected wounds, painful joints in addition to indigestion and liver problems ${ }^{[7}$, ${ }^{33]}$. It is also used for treating expectant mothers with blood clots ${ }^{[7]}$.

\section{Scorpion bites}

Traditional healers have used the stems of this plant family for treating diabetes and high blood sugar ${ }^{[7]}$. The sap is also applied on swollen digits, weeping wounds to stop the oozing, and on wounds with thorns to remove them ${ }^{[7]}$. Locals also believe in the effects of the sap in healing paralysis, where it is applied on the whole body and left for days to aid healing [7]. Another use of this plant is in treating scorpion bites, where a section of the root (specifically from the western side) is pulled, mashed and mixed with lime juice then applied on the site ${ }^{[7]}$. A recent article on the practices in India noted the use of this plant for treating baldness, sprained joints and paralysed limbs ${ }^{[33]}$.

Calotropis procera also has non-medical uses. The leaves were crushed and made into a paste, then used for removing hair from animal feather prior to tanning. Moreover, the barks were burned and used for making gun-powder ${ }^{[5]}$.

\section{Poisonous parts}

Calotropis procera is poisonous all over. The leaves and stem contain calotropin and calatropagenin ${ }^{[7]}$. Its' latex runs throughout the plant, and is acidic in nature with several toxins present in it ${ }^{[35]}$. It contains glycosides, oxalates, proteolytic enzymes and three powerful bacteriolytic enzymes; usacharin, clatoxin, calactin ${ }^{7}$. The presence of a white crytaline substance in the serum named Gigantin has been reported ${ }^{35}$. This chemical has been found to be $15-20$ times more noxious than strychnine ${ }^{[35]}$.

\section{Side effects}

On contact with the skin, the sap causes skin irritation and dermatitis. On ingestion, gastrointestinal irritation ensues, with consequent intestinal stasis ${ }^{[8]}$. Interestestingly, one report mentioned the use of latex extracted from the plant in the commercial preparation of eye tonics ${ }^{34}$. However, several studies report that eye exposure can result in ocular toxicity. The extent of damage can range from kerato-conjunctivitis to complete visual loss [33,34,37]. Calotropis procera can also cause myocardial toxicity, the extent of which depends on the amount of cardio-active steroids ingested. Manifestations can be in the form of dysrhythmias, like sinus bradycardia, premature ventricular contractions, atrioventricular conduction defects, or ventricular tachydysrhythmias [7]. Other possible side effects comprise respiratory paralysis, hyperkalemia and neurological manifestations, including depression, weakness, incoordination, and seizures ${ }^{[36]}$. 


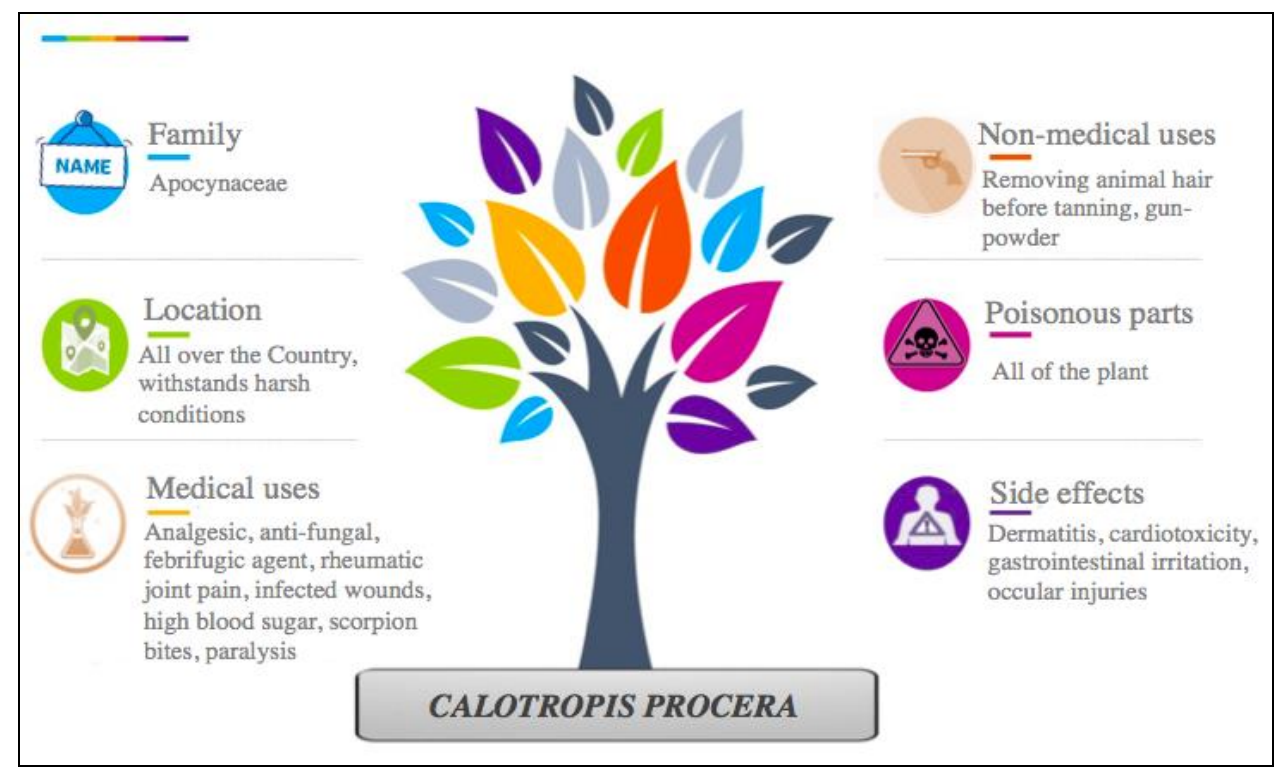

Infograph (6)

\section{Conclusion}

This paper provided a report on the ethno-medicinal use of some of the plants that are available locally and utilized for curing various ailments and states. The majority of this information lies within the minds of elders, thus such reports are essential to document the knowledge pertaining to their use in traditional practice. Traditional and complementary medicine originate from ethno-medicine, and in-depth study of those plants is essential for the scientific community, as it provides basic evidence for the therapeutic value and acknowledges efficacy and safety of those herbs. As the only difference between medicine and poison lies in the dose, awareness and knowledge of the plant's characteristics are essential for whoever is intending to use them.

To sum up, the six plants discussed in this report with their main side effects is as follows: Nerium oleander (cardiac dysrhythmias, neurological and gastrointestinal disturbances), Adenium obesum (cardiac dysrhythmias, neurological and gastrointestinal disturbances, hyperkalaemia), Euphorbia cactus (skin irritation, ocular injuries), Ficus cordata (neurotoxicity, hepatic injury), Datura metel (anticholinergic toxicity) and Calotropis procera (dermatitis, cardiac toxicity, gastrointestinal irritation, ocular injuries).

\section{Disclosure}

The authors declare no conflicts of interest. No funding was received for this study.

\section{Acknowledgement}

The authors would like to thank Dr. B Al Hatali (Ministry of Health- Department of Environmental and Occupational Health) for her guidance and assistance in providing local figures. They would also like to thank Dr. M Al Shamsi (Ministry of Defense- Armed Forces Hospital) \& Dr. A Al Kashmiri (Ministry of Health- Khoula Hospital) for reviewing the article. The authors would also like to extend their gratitude to the staff at Oman Botanic Garden and Natural History Museum for providing resources and plant samples during the period of data collection.

\section{References}

1. Orhan IE. Biotechnological production of plant secondary metabolites, Bentham e-book, 2012, 107-120.

2. Weber AS. Folk Medicine in Oman, International Journal of Arts \& Sciences, Cumberland. 2011; 4(23):237-274.
3. WHO. Global Report on Traditional and Complementary Medicine, 2019

[https://www.who.int/traditional-complementaryintegrativemedicine/WhoGlobalReportOnTraditionalAndCompleme ntaryMedicine2019.pdf?ua=1]

Accessed July $1^{\text {st }} 2020$

4. Dr. Al Hatali B. Department of Environmental and Occupational Health, Ministry of Health (MoH), Oman, 2018.

5. Miller AG, Morris M. Plants of Dhofar, The Southern Region of Oman: Traditional, Economic, and Medicinal Uses, Published by Office of the Adviser for Conservation of the Environment, Diwan of Royal Court, Sultanate of Oman, 1988.

6. Ghazanfar S, Al-Sabahi A. Medicinal plants of northern \& central Oman (Arabia) Economic Botany. 1993; 47(1):89-98.

7. Al Hinai A, Lupton D, Al Issai G. Indigenous knowledge and folk use of medicinal plants in the Eastern Hajar Mountains, Oman, Journal of Medicinal Plants Studies. 2020; 8(4):104- 110.

8. Al Hatali BA. Toxic Plants, In: Al Yazidi M, Al Hatali BA, Al Hajri, NM eds, National Management Guidelines of Poisoning, $3^{\text {rd }}$ ed, Sultanate of Oman, Chp. 2018; 30:251-264.

9. Minns A. California Poison Control Centre: Naturally Occurring Cardiac Glycoside Poisoning, United States of America, 2017.

[https://calpoison.org/news/cardiac-glycoside-poisoning] Accessed July $14^{\text {th }} 2020$

10. Graeme KA. Toxic plant ingestions, In: Auerbach PS, Cushing TA, Harris NS, eds. Auerbach's Wilderness Medicine. 7th ed. Philadelphia, PA: Elsevier; chap, 2017, 65

[http://pennstatehershey.adam.com/content.aspx?producti $\mathrm{d}=117 \&$ pid=1\&gid=002884] Accessed June 30 2020

11. Hossain MA. A review on Adenium obesum: A potential endemic medicinal plant in Oman, Beni-Suef University Journal of Basic and Applied Sciences. 2018; 7(4):559 563.

12. Hossain $\mathrm{M}$ et al. Two new flavonoids from Adenium obesum grown in Oman, Journal of King Saud University-Science. 2017; 29(1):62-69. 
13. Mouza KG, Hossain MA. Determination of total phenolics, flavonoids and antioxidant activity of root crude extracts of Adenium obesum traditionally used for the treatment of bone dislocations and rheumatism, Asian Pacific Journal of Tropical Diseases. 2015; 5(1):155-158.

14. Lockwood D. Dhofar- Adenium obesum, 2017. [https://davidalockwoodphotography.com/2017/04/30/dh ofar-adenium-obecium/] Accessed July $15^{\text {th }} 2020$

15. Haevermans T. In Goodman, S. M. and J.P. Benstead, eds. The Natural History of Madagascar. University of Chicago Press, 2003, 384-391, 1728p.

16. Pascal $\mathrm{O}$ et al. A review of the ethnomedical uses, phytochemistry and pharmacology of the Euphorbia genus, The Pharma Journal. 2017; 6(1):34-39.

17. Kesler C. How do euphorbia plants cause contact dermatitis?, Nursing 2020: The peer-reviewed journal of clinical excellence. 2009; 39(6):13.

18. Stoner J, Rasmussen J. Plant Dermatitis, Journal of the American Academy of Dermatology. 1983; 9(1):1-15.

19. Eke T, Al-Husainy S, Raynor MK. The Spectrum of Ocular Inflammation Caused by Euphorbia Plant Sap, Archives of Ophthalmology. 2000; 118(1):13-16.

20. Sood T, Sharma R. To report a case of euphorbia keratopathy, 2018.

[https://www.researchgate.net/publication/327601788_toreport-a-case-of-euphorbia-keratopathy-2155-9570-

1000749] Accessed July $19^{\text {th }} 2020$

21. Croizat L. Poisonous Euphorbiae, Desert Plant Life. $1935 ; 7: 130$.

22. Jaarsvald EV. Ficus cordata, South Africa National Biodiversity Institute, 2018. [http://pza.sanbi.org/ficuscordata]

23. Hegazy A, Lovett-Doust J. Plant Ecology in the Middle East, Oxford University Press, United Kingdom, 2016.

24. Divakar MC, Al-Siyabi A, Varghese SS, Al- Rubaie M. The Practice of Ethnomedicine in the Northern and Southern Provinces of Oman, Oman Medical Journal. 2016; 31(4):245-252

25. Kuete V, Ngameni B, Fotso Simo CC, Tankeu RK, Ngadjui BT, Meyer JJM et al. Antimicrobial activity of the crude extract and compounds from Ficus chlamydocarp and Ficus cordata (Moraceae), Journal of Ethnopharmacology. 2008; 120:17-24.

26. Olaokun $\mathrm{O}$ et al. Evaluation of the inhibition of carbohydrate hydrolysing enzymes, antioxidant activity and polyphenolic content of extracts of ten African Ficus species (Moraceae) used traditionally to treat diabetes, BMC Complementary and Alternative Medicine, 2013; 13(94).

27. Al-Musayeib $\mathrm{N}$ et al. Chemotaxonomic Diversity of Three Ficus Species: Their Discrimination Using Chemometric Analysis and Their Role in Combating Oxidative Stress, Pharmacognosy Magazine. 2017; 13(3):613-622.

28. Myburgh JG et al. A Nervous Disorder in Cattle, Caused by the Plants Ficus Ingens Var. Ingens and Ficus cordata Subsp. Salicifolia, Onderstepoort Journal of Veterinary Research (OJVR). 1994; 61(2):171-6.

29. Karinho-Betancourt E et al. Phylogenetic correlations among chemical and physical plant defenses change with ontogeny, New Phytologist. 2015; 206(2):796-806.

30. Kanchan T, Atreya A. Datura: The Roadside Poison, Wilderness \& Environmental Medicine. 2016; 27:442443

31. Al Jabri A. E-Flora of the Sultanate of Oman, 2015. [http://omanflora.myspecies.info/en/content/poisonousplants] Accessed June $30^{\text {th }} 2020$

32. Cunningham S. Cunningham's Encyclopedia of Magical Herbs, Llewellyn Publications, Woodbury Minnesota, 2015.

33. Jain VK, Kesarwani D, Yadav V, Sharma K. Calotropisinduced corneal toxicity in Indian medicinal use: A rare case report with review of literature, Journal of Ophthalmic Science \& research. 2020; 58(1):37-39.

34. Thakkar R, Vaghela B, Buddhadev S. A Valuable Plant Calotropis procera Linn in Indian System of Medicine: Ayurveda, An International Journal of Pharmaceutical Sciences. 2014; 5(1):151-163.

35. Waiker S, Srivastava VK. Calotropis induced ocular toxicity, Medical Journal of Armed Forces India. 2015; 71(1):92-94

36. Al Ghadeer H, Al Gethami A, Al Sulaiman H, Bukhari T. Corneal toxicity after self-application of Calotropis procera (Ushaar) latex: Case report and analysis of the active components. Middle East African Journal of Ophthalmology. 2019; 26:40-42.

37. Pandey N, Chandrakar AK, Garg ML, Patel SS. Calotropis procera-induced keratitis, Indian Journal of Ophthalmology. 2009; 57:58-60. 